\title{
Combinatorial Problems in Mathematical Competitions
}




\section{Mathematical Olympiad Series}

ISSN: 1793-8570

Series Editors: Lee Peng Yee (Nanyang Technological University, Singapore)

Xiong Bin (East China Normal University, China)

Published

Vol. 1 A First Step to Mathematical Olympiad Problems

by Derek Holton (University of Otago, New Zealand)

Vol. 2 Problems of Number Theory in Mathematical Competitions by Yu Hong-Bing (Suzhou University, China) translated by Lin Lei (East China Normal University, China)

Vol. 3 Graph Theory

by Xiong Bin (East China Normal University, China) \& Zheng Zhongyi (High School Attached to Fudan University, China) translated by Liu Ruifang, Zhai Mingqing \& Lin Yuanqing (East China Normal University, China)

Vol. 4 Combinatorial Problems in Mathematical Competitions by Yao Zhang (Hunan Normal University, P. R. China)

Vol. 5 Selected Problems of the Vietnamese Olympiad (1962-2009) by Le Hai Chau (Ministry of Education and Training, Vietnam) \& Le Hai Khoi (Nanyang Technology University, Singapore)

Vol. 6 Lecture Notes on Mathematical Olympiad Courses:

For Junior Section (In 2 Volumes)

by $\mathrm{Xu}$ Jiagu 


\section{Yao Zhang \\ Hunan Normal University, P R Cbina}

Combinatorial Problems in Mathematical Competitions 


\section{Published by}

East China Normal University Press

3663 North Zhongshan Road

Shanghai 200062

China

and

World Scientific Publishing Co. Pte. Ltd.

5 Toh Tuck Link, Singapore 596224

USA office: 27 Warren Street, Suite 401-402, Hackensack, NJ 07601

UK office: 57 Shelton Street, Covent Garden, London WC2H 9HE

\section{British Library Cataloguing-in-Publication Data}

A catalogue record for this book is available from the British Library.

\section{COMBINATORIAL PROBLEMS IN MATHEMATICAL COMPETITIONS}

Copyright (C) 2011 by East China Normal University Press and World Scientific Publishing Co. Pte. Ltd.

All rights reserved. This book, or parts thereof, may not be reproduced in any form or by any means, electronic or mechanical, including photocopying, recording or any information storage and retrieval system now known or to be invented, without written permission from the Publisher.

For photocopying of material in this volume, please pay a copying fee through the Copyright Clearance Center, Inc., 222 Rosewood Drive, Danvers, MA 01923, USA. In this case permission to photocopy is not required from the publisher.

ISBN-13 978-981-283-949-7(pbk)

ISBN-10 981-283-949-6(pbk)

Printed in Singapore by Mainland Press Pte Ltd. 


\section{Copy Editors}

NI Ming East China Normal University Press, China

ZHANG Ji World Scientific Publishing Co., Singapore

WONG Fook Sung Temasek Polytechnic, Singapore

KONG Lingzhi East China Normal University Press, China 
This page intentionally left blank 


\section{Introduction}

This book consists of three parts: fundamental knowledge, basic methods and typical problems. These three parts introduce the fundamental knowledge of solving combinatorial problems, the important solutions to combinatorial problems and some typical problems with often-used solutions in the high school mathematical competition respectively.

In each chapter there are necessary examples and exercises with solutions. These examples and exercises are of the same level of difficulty as the China Mathematical League Competitions which are selected from mathematical competitions at home and abroad in recent years. Some test questions are created by the author himself and a few easy questions in China Mathematical Olympiad (CMO) and IMO are also included. In this book, the author pay attention to leading readers to explore, analyze and summarize the ideas and methods of solving combinatorial problems. The readers' mathematical concepts and abilities will be improved remarkably after acquiring knowledge from this book. 
This page intentionally left blank 


\section{Preface}

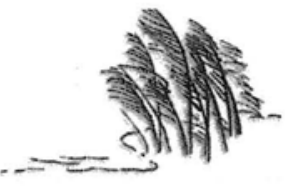

Combinatorial Mathematics has a long history. Thousands of years ago, some simple and interesting combinatorial problems started to be involved in the ancient Chinese masterpieces such as $\mathrm{He} T u$ and Luo Shu. In the recent 20 years, owing to the rapid development of knowledge such as Computer Science, Coding Theory, Programming Theory, Digital Communication and Experimental Designing, a series of theoretical and practical problems need to be solved by discrete mathematics. Moreover, the questions which were raised by the logic of combinatorial mathematics itself and other branches of mathematics, has made the research about combinatorial mathematics to flourish and very rich. The problem-solving techniques and methods are daedal, transforming this ancient mathematical idea into a rigorous mathematical subject.

The combinatorial questions in the mathematical competitions are always straightforward, but the people who solve these problems should be endowed with the power of acute observation, rich imagination and necessarily skills. There are no fixed methods that can be followed, and various questions of different level of difficulties are very rich. Hence, combinatorial questions have been included in different levels of intelligence test and mathematical competition.

This book focus on the combinatorial problems in the mathematics competition, and consists of three parts: fundamental knowledge, basic methods and typical problems. This book is a translation from the author's book of the same title (in Chinese), with a few amendments 
and supplements. It not only emphasizes the fundamental knowledge of solving combinatorial problems in mathematical competitions, but also introduces to the readers the important solutions to combinatorial problems and some typical problems with solutions that are often used.

In the choice of examples and exercises, except the questions which strikingly newer have been selected as far as possible, but the novel test questions which are the same difficult level as the China Mathematical League Competitions in the mathematical competition at home and abroad in recent yeas have been chosen deliberately. Some test questions created by the author himself and a few easy questions in China Mathematical Olympiad (CMO) and IMO are also included. In this book, the author pays attention to leading the readers to explore, analyze and summarize the ideas and methods of solving combinatorial problems. The readers' mathematical concepts and abilities will be improved remarkably after acquiring the knowledge from this book. 


\section{Contents}

Introduction vii

Preface ix

\section{PART ONE Fundamental Knowledge}

Chapter 1 Principles and Formulas of Counting 1

Exercise $1 \quad 16$

Chapter 2 Pigeonhole Principle and Mean Value Principle 20

Exercise 2

Chapter 3 The Generating Functions 33

Exercise 3

Chapter 4 Recurrence Sequence of Numbers $\quad 40$

Exercise 4

\section{PART TWO Basic Method}

Chapter 5 Classification and Method of Fractional Steps 56

Exercise 5

$\begin{array}{lll}\text { Chapter } 6 & \text { Correspondent Method } & 67\end{array}$

Exercise $6 \quad 84$

$\begin{array}{lll}\text { Chapter } 7 & \text { Counting in Two Ways } & 87\end{array}$

Exercise $7 \quad 98$

$\begin{array}{lll}\text { Chapter } 8 & \text { Recurrence Method } & 100\end{array}$

Exercise $8 \quad 109$

Chapter 9 Coloring Method and Evaluation Method 112

Exercise 9 
Chapter 10 Reduction to Absurdity and the Extreme Principle 123 Exercise 10

Chapter 11 Local Adjustment Method

Exercise 11

Chapter 12 Construction Method

Exercise 12

\section{PART THREE Typical Problems}

Chapter 13 Combinatorial Counting Problems

Exercise 13

Chapter 14 Existence Problems and the Proofs of Inequalities in Combinatorial Problems

Exercise 14

Chapter 15 Combinatorial Extremum Problems

Exercise 15

Solutions to Exercises 